\title{
A DOUBLE-BLIND OF THE EFFICACY AND SAFETY OF MILNACIPRAN AND FLUOXETINE IN DEPRESSED INPATIENTS
}

\author{
J.D. Guelfia, M. Ansseaub, E. Corrublea, J.C. Samuelianc, I.Tonellid, A. Tournouxd, Y. Plétand \\ aUniversity Paris XI, Department of Psychiatry, Hôpital Paul Brousse, Villejuif, France ; \\ ${ }^{b}$ Department of Psychatry, CHU du Sart Tilman, Liège, Belgium ; \\ cDepartment of Psychiatry, CHU La Timone, Marseille; \\ dInstitut de Recherche Pierre Fabre, Boulogne, France.
}

KEYWORDS: antidepressant, efficay, fluoxetine, depression, milnacipran

\section{ABSTRACT}

This double-blind, randomised, multicentre study compared the antidepressant efficacy and safety of two doses of milnacipran $(100 \mathrm{mg} /$ day and $200 \mathrm{mg} /$ day $)$ and fluoxetine $(20 \mathrm{mg} /$ day $)$ in 289 inpatients with endogenous depression. After a placebo washout period of 4-7 days, assessments were performed weekly during the first 4 weeks, and then after 6, 8 and 12 weeks, using the 17-item Hamilton Depression Rating Scale (HDRS), the Montgomery - Asberg Depression Rating Scale (MADRS) and the Clinical Global Impression (CGI). HDRS total score was reduced by a mean of 14.8 in the milnacipran $100 \mathrm{mg}$ /day group, 12.9 in the milnacipran $200 \mathrm{mg} /$ day group and $12.1 \mathrm{in}$ the fluoxetine $20 \mathrm{mg} /$ day group. MADRS total score decreased by 17.4, 15.8 and 14.6, respectively. No significant difference could be shown between the three treatment groups for either the HDRS or MADRS total scores. However, the time-by-time change showed a trend in favour of milnacipran $100 \mathrm{mg} /$ day, which was found significantly superior to fluoxetine at day 28 for several converging parameters (MADRS, CGI-3). Overall, efficacy ratings for all parameters were highest for milnacipran $100 \mathrm{mg} /$ day, followed by milnacipran 200 $\mathrm{mg} /$ day and fluoxetine $20 \mathrm{mg} /$ day. Side-effect profiles were not significantly different between groups except for a significantly greater frequency of dose-related increase in heart rate $\geq 100$ bpm in milnacipran recipients and a significantly greater weight loss in fluoxetine recipients. 


\section{Introduction}

Milnacipran, a non-trycyclic cyclopropane, is a new antidepressant which selective inhibits the reuptake of serotonin and noradredaline without any direct effect at any postsynaptic receptor site (Moret et al., 1985). Milnacipran is active in behavioural tests of noradrenergic and serotonergic function and has also shown efficacy in animal models of depression (Stenger et al., 1987; Redmond et al., 1995). Human pharmacokinetic studies have revealed an 8 h plasma halflife and the absence of active metabolites (Puozzo and Leonard, 1996).

Clinical studies of milnacipran have included more than 4000 patients treated with this agent. Among 31 double-blind trials performed in hospitalized or ambulatory patients with major depressive disorder, 14 compared the effects of milnacipran $100 \mathrm{mg} /$ day with those of placebo (three studies), trycyclic antidepressants (TCAs; nine studies) and selective serotonin reuptake inhibitors (SSRI; two studies) (Kasper et al., 1996; López-Ibor et al., 1996).

Milnacipran has been shown to be effective in major depressive episodes (adults and the elderly) at a dosage of $100 \mathrm{mg} /$ day, i.e. two $50 \mathrm{mg}$ capsules given with meals morning and evening. At this dosage, milnacipran has been shown to be superior to placebo (Lecrubier et al., 1996) and as efficacious as TCAs. In nine comparative trials versus TCAs, milnacipran was found equivalent as in one Clerc's study (1990) with the exception of one trial where clomipramine was found superior (Kasper et al., 1996). Previous studies comparing milnacipran 100 or $200 \mathrm{mg} /$ day with SSRis have included three trials with fluvoxamine (Lôpez- Ibor et al., 1996) and one with fluoxetine (Ansseau et al., 1994).

In the two trials comparing milnacipran and fluvoxamine $(200 \mathrm{mg} /$ day $)$, the daily doses of milnacipran ranged between 200 and $300 \mathrm{mg}$, and no differences between treatments were found (Ansseau et al., 1991). Nevertheless, it was later shown clearly that these high doses of milnacipran were less effective than the $100 \mathrm{mg}$ dose (unpublished data, Institut de Recherche, Pierre Fabre). Hence, the third study compared milnacipran $100 \mathrm{mg} /$ day with fluvoxamine 200 $\mathrm{mg} /$ day in a sample of 113 patients over a 6-week period (López-lbor et al., 1996). Although the difference in HDRS score at end-point was not statistically significant between treatments, there was a lack of statistical power and therefore the magnitude of the difference, in favour of milnacipran, was deemed interesting in clinical terms $(\Delta$ HDRS $=2.9$ points, difference in response rate on HDRS $=+16 \%$ ). The only study comparing milnacipran with fluoxetine 20 $\mathrm{mg} /$ day (including 190 patients treated for 6 weeks) demonstrated an advantage for fluoxetine $(\triangle$ MADRS $=3.4$ points, difference in response rate on MADRS $=22 \%$ ) (Ansseau et al., 1994). However, in this study milnacipran $100 \mathrm{mg}$ was administered once daily, and it has been shown subsequently that a once-daily regimen is inadequate because milnacipran has a relatively short half-life $\left(t_{1 / 2}=8 \mathrm{~h}\right)$ and no active metabolite (Puozzo and Leonard, 1996). In a separate study, twice-daily administration yielded a $20 \%$ difference in HDRS response rate compared with oncedaily administration in the morning (Institut de Recherche, Pierre Fabre, unpublished data).

In view of the design of the present study, this is the first fair comparison of milnacipran and fluoxetine because both drugs were administered according to the usual recommended dosage regimen. 


\section{Methods}

This multicentre, randomized double-blind study was concluded by 60 centres ( 47 in France, 13 in Belgium). The number of investigators was between one and six per centre. The number of patients per centre was between one and 26. After a 4- to 7-day placebo washout period, patients were randomized in three parallel groups receiving milnacipran $100 \mathrm{mg} /$ day $(50 \mathrm{mg}$ in the morning and in the evening; $n=100$ patients), milnacipran $200 \mathrm{mg} /$ day (100 $\mathrm{mg}$ in the morning and in the evening $\mathrm{n}=100$ ) or fluoxetine $200 \mathrm{mg} /$ day $(20 \mathrm{mg}$ in the morning and placebo in the evening; $n=100$ ) in a double-blind manner for 12 weeks. Assessments were performed weekly during the first 4 weeks, and subsequently, after 6, 8 and 12 weeks.

The 289 inpatients (95 men and 194 women aged 18-70 years) included in the study fulfilled DSM III-R criteria for major depression (American Psychiatric Association, 1987). All patients had been depressed for less than 3 months, had a minimum score of 22 on the 17-item Hamilton Depression Rating Scale (HDRS) (Hamilton, 1960) at the end of the washout period, and fulfilled endogenous criteria according to the Newcastle Scale (score $\geq 6$ ) (Roth et al., 1983) or to HDRS specific endogenous subscore (score $\geq 8$ ) (Thase et al., 1983). Patients were moderately to extremely ill according to the first item of the Clinical Global Impression (CGI) (Guy, 1976). Exclusion criteria were : serious or uncontrolled medical illness; no remission between episodes; depression with psychotic features, dysthymia; personality disorders; lack of response to two antidepressants; patients requiring electroconvulsive therapy or neuroleptics; major risk of suicide; schizophrenia and dependence on psychoactive substances (DSM III-R) during the previous 6 months; treatment with monoamine oxidase (MAO)-inhibitors in the 2 weeks before inclusion; administration of fluoxetine or thymoregulators in th 4 weeks before inclusion; longactive neuroleptics or electroconvulsive therapy in the 3months before inclusion; pregnancy, lactation and lack of contraception in non-menopausal women. All patients were fully informed and provided written informed consent (approval was obtained from the Ethical Review Comittees of Paris, Cochin and Liège). All patients were hospitalized for the first 2 weeks of treatment.

\section{COMEDICATION}

Psychotropic drugs were not allowed, except oxazepam in daily doses $\leq 50 \mathrm{mg} /$ day or chloral hydrate in daily doses $<2 \mathrm{~g} /$ day in case of anxiety and/or insomnia.

\section{ASSESSMENTS}

The main parameter for efficacy was the change in total score on the 17-item HDRS (Hamilton, 1960) between baseline and end-point. Secondary efficacy parameters were the Montgomery Asberg Depression Rating Scale (MADRS) (Montgomery and Asberg, 1979) and CGI (Guy, 1976) total scores. To access and improve interrater reliability session using patient videotape have been organized. Those patients whose total HDRS or MADRS score, respectively, decreased by $50 \%$ from baseline were considered as 'responders'. 
Adverse events were recorded by open questioning at baseline and at each visit during the study. Their severity was rated as mild, moderate or severe, and their onset, frequency, duration and evolution were recorded. All adverse events were coded according to the WHO-ART dictionary.

\section{STATISTICAL ANALYSIS}

Descriptive analysis of the population and comparability of groups were studies using means (and standard deviations) and ANOVAs for quantitative variables, frequency and percentages, chi-squared global tests or extended Fisher's exact tests for qualitative variables.

Efficacy analyses are (1) Intent-to-Treat (ITT) analyses (all randomized patients who received study drug): Last observation carried forwards (LOCF) for end-point analysis, observed case (OC) for analysis by visit, and (2) per protocol (PP) analyses (all randomized patients who completed at least a 14 days treatment period, without major protocol violations).

The HDRS total and factor scores and the MADRS total score were analysed parametrically at each time point when the scales were rated. Analyses of covariance were performed, with country and baseline value as covariates. On the HDRS and MADRS, patients whose total score decreased by $50 \%$ or more from baseline were considered as responders.

Safety analysis was performed using X2 or fisher's exact test for comparisons between groups.

All tests of hypotheses were two-sided. The results were considered to be statistically significant at the alpha risk level of 0.05 .

\section{Results}

A total of 311 patients were pre-included in this study. Among them, 300 were randomized, and 289 included in the ITT analysis: 93 patients in the milnacipran $100 \mathrm{mg} /$ day group, 96 in the milnacipran $200 \mathrm{mg} /$ day group, and 100 in the fluoxetine $20 \mathrm{mg}$ /day group. The PP analysis was performed on 237 patients: 79 patients in the milnacipran $100 \mathrm{mg} /$ day group, 75 in the milnacipran $100 \mathrm{mg}$ /day group, 75 in the milnacipran $200 \mathrm{mg} /$ day group, and 83 in the fluoxetine $200 \mathrm{mg}$ /day group.

\section{COMPARABILITY OF STUDY GROUPS AT BASELINE}

There were no significant differences at baseline between the three treatment groups with respect to demographic data, psychiatric history other than depression, medical and surgical history, time elapsed since first episode, duration of the current episode, or HDRS, MADRS and CGI-1 (severity of illness) scores (Table 1).

However there were significantly $(P<0.05)$ more patients at baseline in the milnacipran 200 $\mathrm{mg} /$ day versus the other two treatment groups who had made at least one suicide attempt and who had experienced recurrent episodes of depression. 
Table 1. Mean ( $\pm S D$ ) baseline characteristics of patients treated with milnacipran $100 \mathrm{mg} /$ day, milnacipran $200 \mathrm{mg} /$ day or fluoxetine $20 \mathrm{mg} /$ day

\begin{tabular}{|c|c|c|c|c|}
\hline Parameter & $\begin{array}{c}\text { Milnacipran } \\
100 \text { mg/day } \\
(n=93)\end{array}$ & $\begin{array}{c}\text { Milnacipran } \\
200 \text { mg/day } \\
(n=96)\end{array}$ & $\begin{array}{c}\text { Fluoxetine } \\
20 \mathrm{mg} / \text { day } \\
(n=100)\end{array}$ & $P$ value \\
\hline Women/men ${ }^{\mathrm{b}}$ & $60 / 40$ & $66 / 34$ & $75 / 25$ & NS \\
\hline Age (years) & $45.6(12.4)$ & $45.2(12.5)$ & $45.8(12.8)$ & NS \\
\hline $\begin{array}{l}\text { Time since first episode } \\
\text { (years) }\end{array}$ & $9.4(9.1)$ & $8.3(8.1)$ & $7.0(7.9)$ & NS \\
\hline $\begin{array}{l}\text { Time elapsed since } \\
\text { previous episode (years) }\end{array}$ & $4.9(5.0)$ & $6.4(6.8)$ & $2.6(1.9)$ & 0.003 \\
\hline $\begin{array}{l}\text { Duration of current episode } \\
\text { (weeks) }\end{array}$ & $7.1(5.2)$ & $8.7(9.3)$ & $9.5(15.5)$ & NS \\
\hline $\begin{array}{l}\text { HDRS total score } \\
\text { CGI-1 }\end{array}$ & $27.9(3.8)$ & $27.7(4.4)$ & $27.4(4)$ & NS \\
\hline severely ill & $30 \%$ & $33 \%$ & $39 \%$ & NS \\
\hline markedly ill & $62 \%$ & $59 \%$ & $57 \%$ & NS \\
\hline MADRS score & $32.2(5.6)$ & $31.9(5.6)$ & $32.1(5.9)$ & NS \\
\hline $\begin{array}{l}\text { Previous suicide attempts } \\
\text { Previous episode }\end{array}$ & $41 \%$ & $51 \%$ & $32 \%$ & 0.03 \\
\hline no & $18 \%$ & $6 \%$ & $20 \%$ & \\
\hline yes & $82 \%$ & $94 \%$ & $80 \%$ & 0.02 \\
\hline
\end{tabular}

$n$ included in the ITT analysis; NS not significant; aoverall comparison; brandomised patients.

Table 2. Percentage (and number) of patients withdrawing and reasons for withdrawal from treatment with milnacipran $100 \mathrm{mg} /$ day, milnacipran $200 \mathrm{mg} /$ day or fluoxetine $20 \mathrm{mg} /$ day

\begin{tabular}{lccc} 
Reason & $\begin{array}{c}\text { Milnacipran } 100 \mathrm{mg} / \text { day } \\
(n=93)\end{array}$ & $\begin{array}{c}\text { Milnacipran } 200 \mathrm{mg} / \text { day } \\
(n=96)\end{array}$ & $\begin{array}{c}\text { Fluoxetine } 20 \mathrm{mg} / \text { day } \\
(n=100)\end{array}$ \\
\hline Patient decision & $21.5 \%(20)$ & $26.0 \%(25)$ & $19.0 \%(19)$ \\
Lack of response & $17.2 \%(16)$ & $21.9 \%(21)$ & $24.0 \%(24)$ \\
Adverse reaction & $2.2 \%(2)$ & $5.2 \%(5)$ & $6.0 \%(6)$ \\
Suicide attempts & $4.3 \%(4)$ & $1 \%(1)$ & $5 \%(5)$ \\
Suicides & $1.1 \%(1)$ & $1 \%(1)$ & $1 \%(1)$ \\
Other serious adverse event & $4.3 \%(4)$ & $5.2 \%(5)$ & $6.0 \%(6)$ \\
Intercurrent illness & $1.1 \%(1)$ & $4.2 \%(4)$ & $1.0 \%(1)$ \\
Lost to follow-up & $6.5 \%(6)$ & $3.1 \%(93)$ & $4.0 \%(4)$ \\
Other reason & $9.7 \%(9)$ & $8.3 \%(8)$ & $12.0 \%(12)$ \\
Total & $44.1 \%(41)$ & $49.0 \%(47)$ & $50.0 \%(50)$
\end{tabular}

\section{STUDY COMPLETION AND DROP-OUTS}

The 12-week double-blind period of the study was completed by $56 \%$ of patients in the milnacipran $100 \mathrm{mg} /$ day group, $51 \%$ in the milnacipran $200 \mathrm{mg}$ /day group and $50 \%$ in the fluoxetine group.

Table 2 summarises the reasons for treatment withdrawal in each group. There were no statistically significant differences between groups with respect to the rates and reasons for withdrawal. However, there was a tendency for more patients in the fluoxetine group (6\%) to withdraw prematurely because of adverse events; the percentage of patients to withdraw for this reason was lowest in the milnacipran $100 \mathrm{mg} /$ day group (2.2\%). 
Table 3. Efficacy of treatment with milnacipran $100 \mathrm{mg} /$ day, milnacipran $200 \mathrm{mg} /$ day or fluoxetine 200 $\mathrm{mg} /$ day (intent-to-treat population)

\begin{tabular}{|c|c|c|c|c|}
\hline & $\begin{array}{l}\text { Milnacipran } \\
100 \text { mg/day }\end{array}$ & $\begin{array}{l}\text { Milnacipran } \\
200 \text { mg/day }\end{array}$ & $\begin{array}{l}\text { Fluoxetine } \\
20 \mathrm{mg} / \text { day }\end{array}$ & $P$ value $^{b}$ \\
\hline \multicolumn{5}{|l|}{ HDRS } \\
\hline Initial score DO & $\begin{array}{c}27.8(3.7) \\
(n=92)\end{array}$ & $\begin{array}{c}27.7(4.4) \\
(n=96)\end{array}$ & $\begin{array}{l}27.4(4.0) \\
(n=100)\end{array}$ & NS \\
\hline Final score D84 & $\begin{array}{l}8.3(6.5) \\
(n=53)\end{array}$ & $\begin{array}{l}7.4(6.4) \\
(n=52)\end{array}$ & $\begin{array}{c}9(6.5) \\
(n=54)\end{array}$ & NS \\
\hline$\Delta: D 28-D 0$ & $\begin{array}{c}-15.2 \\
(n=78)\end{array}$ & $\begin{array}{c}-14.0 \\
(n=73)\end{array}$ & $\begin{array}{c}-12.4 \\
(n=77)\end{array}$ & 0.06 \\
\hline$\Delta:$ end-point - DO & $\begin{array}{c}-14.8(9.8) \\
(n=92)\end{array}$ & $\begin{array}{c}-12.9(11.4) \\
(n=96)\end{array}$ & $\begin{array}{c}-12.1(10.0) \\
(n=100)\end{array}$ & NS \\
\hline Responders ${ }^{a}$ & $(n=92)$ & $\begin{array}{c}54.2 \\
(n=96)\end{array}$ & $\begin{array}{c}51 \\
(n=100)\end{array}$ & NS \\
\hline \multicolumn{5}{|l|}{ MADRS } \\
\hline Initial score DO & $\begin{array}{c}32.23(5.6) \\
(n=92)\end{array}$ & $\begin{array}{l}32(5.6) \\
(n=96)\end{array}$ & $\begin{array}{l}32.1(5.9) \\
(n=100)\end{array}$ & NS \\
\hline Final score & $\begin{array}{l}9.1(8.4) \\
(n=54)\end{array}$ & $\begin{array}{c}8(8.0) \\
(n=52)\end{array}$ & $\begin{array}{l}10.1(8.8) \\
(n=54)\end{array}$ & NS \\
\hline$\Delta:$ D28 - D0 & $\begin{array}{c}-18.2 \\
(n=78)\end{array}$ & $\begin{array}{c}-16.3 \\
(n=73)\end{array}$ & $\begin{array}{c}-14.4 \\
(n=77)\end{array}$ & 0.04 \\
\hline$\Delta$ : end-point - DO & $\begin{array}{c}-17.4(12.3) \\
(n=92)\end{array}$ & $\begin{array}{c}-15.8(13.2) \\
(n=96)\end{array}$ & $\begin{array}{c}-4.6(12.1) \\
(n=100)\end{array}$ & NS \\
\hline Responders $^{\circ}$ & $\begin{array}{c}64.1 \\
(n=92)\end{array}$ & $\begin{array}{c}55.2 \\
(n=96)\end{array}$ & $\begin{array}{c}49.0 \\
(n=100)\end{array}$ & NS \\
\hline
\end{tabular}

All data mean \pm SD unless specified otherwise. aPercentage of patients whose total score decreased by $\geq 50 \%$; bOverall comparison.

NS, not significant; data missing for 1 patient.

\section{COMEDICATION}

The most frequent concomitant medication used during the study were sedative/hypnotics, mainly benzodiazepines, prescribed to $80 \%$ of the patients. Oxazepam, proposed in the protocol as the preferable benzodiazepine, represents two thirds of this class, far ahead of clorazepate and prazepam.

\section{EFFICACY}

HDRS. HDRS total score for each of the three treatment groups is shown in Figure 1. Mean HDRS total score (Table 3 ) decreased significantly between D0 and the end of treatment and between D0 and each visit in all groups $(P<0.001)$.

There was no significant difference between groups for the change in HDRS total score between D0 and end-point. However, in the intent-to-treat (ITT) analysis there was a trend in favour of milnacipran $100 \mathrm{mg} /$ day with respect to the change between D0 and D28 $(P=0.06)$, and the difference in the per protocol (PP) analysis was statistically significant (milnacipran 100 $\mathrm{mg} /$ day : HDRS score $=28.1$ at baseline, change D28 - D0 $=-15.2$; milnacipran $200 \mathrm{mg} /$ day: baseline score $=28$, change $=-14.4$; fluoxetine $200 \mathrm{mg} /$ day : baseline score $=27.4$, change $=$ $12.1)$ between D0 and D28 ( $P=0.03)$. On the HDRS, a response ( $\geq 50 \%$ decreased in total score from baseline) by end-point was recorded in $62 \%$ of patients treated with milnacipran 100 $\mathrm{mg} /$ day, $54 \%$ of those treated with milnacipran $200 \mathrm{mg}$ /day and $51 \%$ of those treated with fluoxetine $20 \mathrm{mg} /$ day (not significant). No significant difference was observed between 
treatment groups in the ITT analysis of HDRS factors (Guy, 1976); however, in the PP analysis there was a significant difference for the 'anxiety/somatisation' factor, observed between D0 and d28 showing a greater improvement with milnacipran $100 \mathrm{mg} /$ day (-4.6) and $200 \mathrm{mg} /$ day $(-4.5)$ than with fluoxetine ( -3.4$),(P=0.02$ and $P=0.03$ respectively).

MADRS. In each treatment group, significant decreases from baseline were observed in the MADRS total score between D0 and each visit $(P<0.001)$. A significant difference was observed for the change between D0 and D28 in MADRS total score in ITT $(P=0.04)$ and PP analysis $(P=$ 0.02) showing a greater improvement with milnacipran $100 \mathrm{mg} /$ day compared with fluoxetine $200 \mathrm{mg} /$ day. However, at end-point, this difference did not reach the significance level.

The percentage of MADRS responders at end-point (decreased of total score above 50\%) was $64 \%$ in the milnacipran $100 \mathrm{mg}$ /day group, $55 \%$ in the milnacipran $200 \mathrm{mg} /$ day group, and $49 \%$ in the fluoxetine group. The difference between milnacipran $100 \mathrm{mg} /$ day and fluoxetine was statistically significant $(P=0.04)$.

In summary, the three compounds were not different at end-point, although milnacipran $100 /$ day was more efficacious on the MADRS at D28 compared with fluoxetine $20 \mathrm{mg}$ /day.

CGI. With respect to three CGI factors (severity of illness, global impression and therapeutic index), there was no significant difference between treatment groups at any of the measured time points (ITT and PP analyses); however, a significant $(P=0.01)$ difference between groups was observed at D28 for CGI-3 (therapeutic index), the percentage of very good results being greater in the milnacipran $100 \mathrm{mg} /$ day group (45\%) than in the milnacipran $200 \mathrm{mg} /$ day (22\%) and fluoxetine (14\%) groups. Moreover, at D28 there was a significant ( $P=0.03$, PP analysis) difference for CGI-2 (global impression), the percentage of patients who were 'very much improved' being greater in the milnacipran $100 \mathrm{mg} /$ day group (39\%) than in the milnacipran $200 \mathrm{mg} /$ day (28\%) and fluoxetine (14\%) groups.

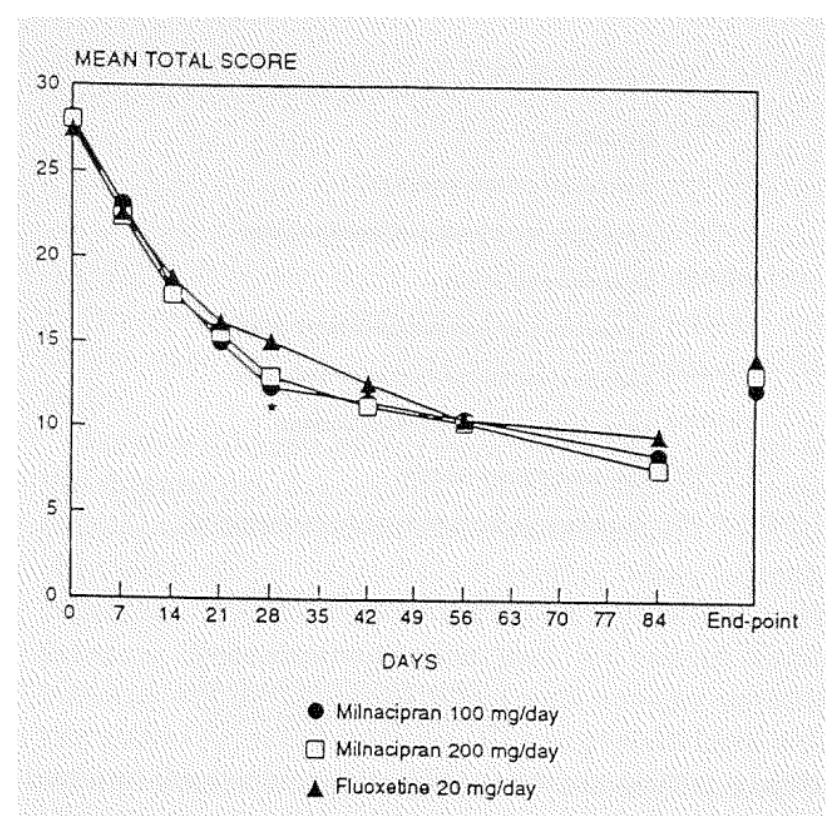

Figure1. Mean Hamilton Depression Rating scale total scores in th per protocol population (*significantly different between groups). 


\section{SAFETY}

The most frequent spontaneously reported adverse events (Figure 2) were as follows: milnacipran $100 \mathrm{mg} /$ day - abdominal pain (13\%), constipation (10\%) and headache (9\%); milnacipran 200/day - headache (8\%), abdominal pain (7\%), and nausea and vomiting (7\%); fluoxetine - abdominal pain (11\%), nausea (11\%), anxiety (10\%) and insomnia (10\%). In terms of cardiovascular safety, there was a statistically significant $(\mathrm{P}=0.03)$ difference between the three treatment groups for tachycardia (heart rate $100 \mathrm{bpm}$ ) (fluoxetine, 0\%; milnacipran 100 $\mathrm{mg} /$ day, 3\%; milnacipran $200 \mathrm{mg} /$ day, 6\%). There were no significant changes in blood pressure. In terms of body weight, a significant $(P=0.05)$ difference between treatment groups was observed at D56, with a greater change with fluoxetine $(-1.4 \mathrm{~kg})$ than with either milnacipran $100 \mathrm{mg} /$ day (no weight change) $(P=0.02$ versus fluoxetine) or milnacipran 200 $\mathrm{mg} /$ day $(-0.3 \mathrm{~kg})(P=0.06$ versus fluoxetine $)$.

Forty serious adverse events (SAEs) were reported during the study: 14 in the milnacipran 100 $\mathrm{mg}$ /day group, $10 \mathrm{in}$ the milnacipran $200 \mathrm{mg} /$ day group, 13 in the fluoxetine group, and three during the washout period. Most of the SAEs in the three treatment groups were related to the treated disease (suicide attempt, suicide, worsening of depression and anxiety). In the milnacipran $200 \mathrm{mg} /$ day group, there were fewer cases of attempted suicide $(n=1)$ and worsening of depression $(n=2)$ than in both the milnacipran $100 \mathrm{mg} /$ day $(n=4$ and $n=5$, respectively) groups. There was ine suicide by hanging in each group : in the milnacipran 100 $\mathrm{mg} /$ day group, the patient was lost to follow-up, and she died 4 weeks after the theoretical end of the study treatment. In the milnacipran $200 \mathrm{mg}$ /day group, after an initial improvement (HDRS score decreased from 30 to 10 at week 2), the depression aggravated, requiring oxazepam, and the patient committed suicide after 4 weeks (HDRS score : 29). In the fluoxetine group, the suicide occurred after 6 weeks of treatment without noticeable HDRS modification (score at baseline $=29$, at week $6=22$ ), in spite of concomitant treatment with oxazepam + chloral.

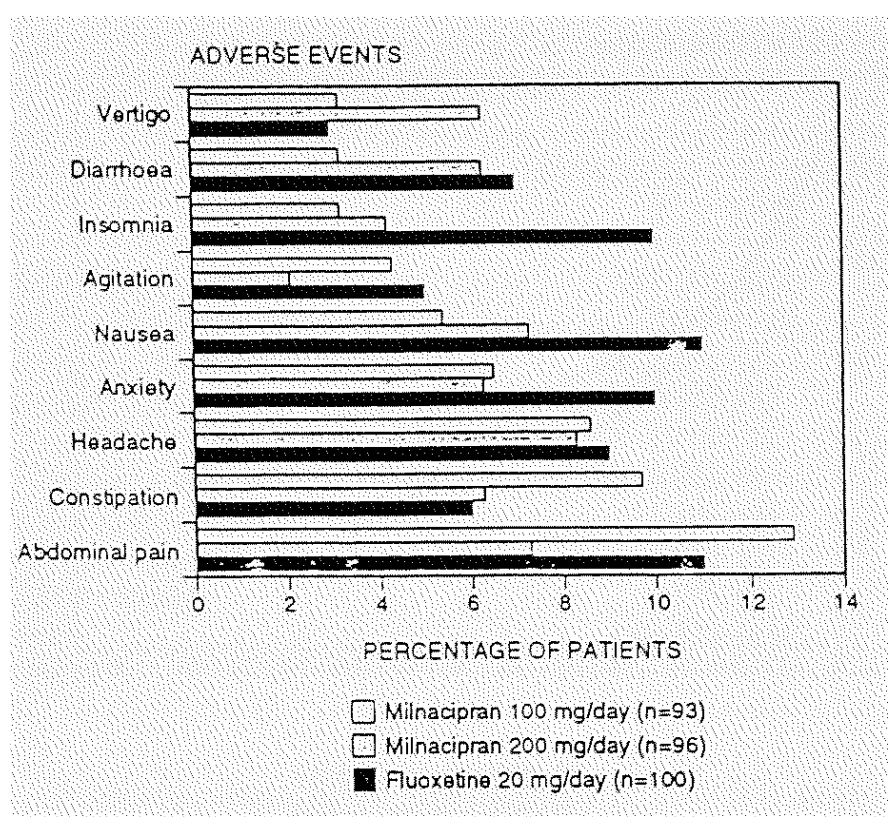

Figure 2. Type and frequency of spontaneously reported adverse events. 


\section{Discussion}

The present study was designed to evaluate the relative efficacy of two doses of milnacipran 100 $\mathrm{mg} /$ day and $200 \mathrm{mg} /$ day and a standard reference treatment, fluoxetine $20 \mathrm{mg} /$ day, in severely depressed inpatients.

Although not statistically significant, a difference in favour of milnacipran $100 \mathrm{mg}$ was found on HDRS, the primary efficacy parameter.

In addition, there was a consistent trend in all the clinical parameters for an efficacy rank order favouring milnacipran $100 \mathrm{mg}$ over $200 \mathrm{mg}$ and fluoxetine $20 \mathrm{mg}$ (milnacipran $100 \mathrm{mg} /$ day > milnacipran $200 \mathrm{mg}$ /day > fluoxetine $20 \mathrm{mg}$ /day). Significant differences were found in favour of milnacipran $100 \mathrm{mg}$ on HDRS (total score) and CGI-3 (therapeutic index) at D28, although they did not persist up to the end-point.

This study provides a direct comparison of milnacipran administered at daily doses of $100 \mathrm{mg}$ and $200 \mathrm{mg}$. Although patients allocated to the highest dosage group met several criteria supporting a more severe pre-existing depression status (number of previous suicide attempts, percentage of patients with recurring depressive episodes), there was no trend in favour of the $200 \mathrm{mg}$ dose being more active than $100 \mathrm{mg}$ /day. Thus, the hypothesis that a higher daily dose of milnacipran may be more effective in severely depressed patients is not supported.

These date are nevertheless consistent with those observed in a fixed-dose parallel-group study comparing milnacipran 50,100 and $200 \mathrm{mg} /$ day with placebo in outpatients (unpublished data) and with those from several active-comparator studies using either 100 or $200 \mathrm{mg}$ /day in which the lower dose yielded consistently better results than the higher dose.

While the patient groups assigned to treatment with either 100 or $200 \mathrm{mg} /$ day doses of milnacipran were not strictly comparable in this study, the results suggest that increasing the daily dose, unlike the situation with other antidepressants (Puech, 1996), does not lead to a higher rate of efficacy.

In the present study, even if a trend exists in favour of milnacipran $100 \mathrm{mg} / \mathrm{day}$, none of the milnacipran doses was significantly superior to fluoxetine with respect to the main efficacy parameter, HDRS total score. An important point to consider is the severity of the depression in this sample. The patients included were moderately to severely depressed, according to the inclusion criteria: hospitalization during at least one week, a minimum score of 22 on the HDRS17, endogenous criteria according to the Newcastle Scale or the HDRS specific endogenous subscore, A CGI 1 (severity) rated moderately to extremely ill and the absence of DSM-III-R psychotic features (which presence is known to require the association of antidepressant and neuroleptic drugs). Other severity criteria may have been chosen, for example, DSM-III-R melancholia criteria (Clerc et al. 1994; Guelfi et al. 1995; Benkert et al. 1996). However, it should be stated that, as reflected by the HDRS and MADRS inclusion scores (34\% of the patients having a HDRS score between 22 and 25, $41 \%$ between 25 and 30, and 25\% higher than 30), our criteria are relevant in terms of inclusion of moderate to severe depression.

Although questions may be raised with regard to the validity of drawing firm conclusions in the absence of a placebo reference, the results from this study should be considered along with 
those from other studies. First, both the difference in HDRS between baseline and end-point and the percentage of responders in the fluoxetine group in the present trial are quite similar to those reported in published placebo-controlled studies of fluoxetine administered at the same dosage in similar populations (Tollefson et al., 1994; Hall, 1988). Similar findings have also been reported in active-comparator studies with fluoxetine (Beasley et al., 1993; Song et al., 1993). Therefore, it is unlikely that the difference between milnacipran and fluoxetine observed in this study is cause by an insufficient efficacy of fluoxetine in this population. Moreover, the $20 \mathrm{mg} /$ day fluoxetine dosage has been found as effective as higher (60 mg/day) dosages (Schweizer et al., 1990) and has been considered as the optimal one (Altamura et al., 1988). However, it can not be excluded that severely depressed patients could benefit from other treatment strategies or doses of fluoxetine, compared with milder forms. Nevertheless, a study of fluoxetine $40 \mathrm{mg} /$ day in severely depressed patients has shown identical results as the present study (Clerc et al., 1994).

Despite a relatively large sample size $(n=289)$ the observed differences were not statistically significant. Nevertheless, the magnitude of the difference at end-point, in particular between the milnacipran $100 \mathrm{mg} /$ day and fluoxetine $20 \mathrm{mg}$ /day groups (2.7 points on HDRS and 11\% responders), may be of clinical value and it may reasonably be asked whether a slightly more powerful study would have led to statistically significant results, not only at one of the time points as shown here, but also at end-point.

Serious adverse events were generally related to the depression. Ten suicide attempts and three completed suicides occurred in this study, one in each treatment group: these three patients were severely depressed (baseline HDRS scores were 29-30), with previous depressive episodes, and, for two of them, previous suicide attempts. Even with a major suicidal risk as an exclusion criterion, how to project from suicide attempts remains a critical issue in all the studies including severely depressed patients.

In terms of safety profiles, there were no differences between milnacipran and fluoxetine, with the exception of tachycardia, which was significantly more frequent in milnacipran-treated patients, and anxiety, insomnia and weight loss, which were more frequent in patients who received fluoxetine $20 \mathrm{mg} /$ day. Tachycardia, which appears to be dose-related, was probably associated with the noradrenergic component of milnacipran; this effect appeared to be moderate, reversible and well tolerated.

\section{Conclusion}

This 12-week double-blind, three-arm, randomised study in 289 inpatients with endogenous depression showed that milnacipran, administered at doses of 100 and $200 \mathrm{mg} /$ day in a twicedaily regimen, is at least as effective and well tolerated as fluoxetine $200 \mathrm{mg} /$ day in the treatment of major depressive episode. Although no statistically significant differences were recorded between treatments, there was a consistent tendency suggesting that milnacipran at a dosage of $100 \mathrm{mg} /$ day may be a better candidate than either milnacipran $200 \mathrm{mg} /$ day or fluoxetine $20 \mathrm{mg} /$ day for the treatment of depression in terms of both efficacy and safety. 


\section{References}

Altamura AC, Montgomery SA, Wernicke JF (1988). The evidence for $20 \mathrm{mg}$ a day of fluoxetine as the Optimal Dose in the Treatment of Depression. Br J Psychiatry 153 (suppl 3):109-112.

American Psychiatric Association (1987). Diagnostic and statistical manual of mental disorders. 3rd rev. ed. Washington DC; American Psychiatric Association.

Anseau M, von Fronckell R, Gérard MA, Mertens C, De Wilde J, Botte L, et al. (1991). Interest of a loading dose of milnacipran in endogenous depressive patients. Eur Neuropsychopharmacol 1:113-121.

Ansseau M, Papart P, Troisfontaines B, Bartholome F, Bataille M, Charles G, et al. (1994). Controlled comparison of milnacipran and fluoxetine in major depression. Psychopharmacology 114:131-137.

Beasley Jr CM, Holman SL, Potvin JH (1993). Fluoxetine compared with imipramine in the treatment of inpatient depression. Ann Clin Psychiatry 5:199-208.

Benkert O, Gründer G, Wetzel H, Hackett DA (1996). A randomized double-blind comparison of a rapidly escalating dose of venlafaxine and imipramine in inpatients with major depression and melancholia. $\mathrm{P}$ Psychiatr Res 30:441-451.

Clerc GE, Pagot JM, Bouchard JM, Oulès J, Guilbert M. Assicot M, et al. (1990). Therapeutic contribution of milnacipran and of clomipramine during a 3-month treatment: results of a comparative study. Psychiatric Psychobiologie 5:137-143.

Clerc GE, Ruimy P, Verdeau-Paillès J (1994). A double-blind comparison of venlafaxine and fluoxetine in patients hospitalized for major depression and melancholia. Int Clin Psychopharmacol 9:136-143.

Guelfi JD, White C, Hackett D, Guichoux JY, Magni G (1995). Effectiveness of venlafaxine in patients hospitalized for major depression and melancholia. J Clin Psychiatry 56:450-458.

Guy W (1976. Early clinical drug evaluation units. Assessment manual for pasychopharmacology. National Institute of Mental Health. Rockville, Maryland, USA.

Hall J (1988). Fluoxetine: efficacy against placebo and by dose - an overview. Br J Psychiatry 153 (suppl 3):59-63.

Hamilton M (1960). A rating scale for depression. J Neurol Neurosurg Psychiatry 23:56-62.

Kasper S, Plétan Y, Solles A, Tournoux A (1996). Comparative studies with milnacipran and tricyclic antidepressants in the treatment of patients with major depression : a summary of clinical trial results. International Clinical Psychopharmacology 11 (suppl 4):35-39.

Lecrubier Y, Plétan Y, Solles A, Tournoux A, Magne V (1996). Clinical efficacy of milnacipran. Placebocontrolled trials. Int CLin Psychopharmacol 11 (suppl 4):29-33.

Lopez-Ibor J, Guelfi JD, Plétan Y, Tounoux A, Prost JF (1996). Milnacipran and selective serotonin reuptake inhibitors in major depression. Int Clin Psychopharmacol 11(suppl 4):41-46.

Montgomery S, Asberg M (1979). A new depression scale designed to be sensitive to change. $\mathrm{Br} \mathrm{J}$ Psychiatry 134:382-389.

Moret C, Charveron M, Finberg JPM, Couzinier JP, Briley M (1985). Biochemical profile of mildalcipran (F2207), a potential fourth generation antidepressant drug. Neuropharmacology 24:1211-1219.

Puech AJ (1996). A double action antidepressant: venlafaxine. Eur Neuropsychopharmacol 6 (suppl 4):45. 
Puozzo C, Leonard BE (1996). Pharmacokinetics of milnacipran in comparison with other antidepressants. Int Clin Psychopharmacol 11 (suppl 4):15-27.

Redmond AM, Kelly JP, Leonard BE (1995). The behavioural effects of milnacipran in the olfactory bulbectomised rad model of depression. Med Sci Res 23:533-534.

Roth M, Gurney C, Mountjoy CQ (1983). The Newcastle Rating Scale. Acta Psychiatr Scand 110 (suppl 1):42-54.

Schweizer E, Rickels K, Amsterdam J, Fox I, Puzzuoli G, Weise C (1990). What constitutes an adequate antidepressant trial for fluoxetine? J Clin Psychiatry 51:8-11.

Song F, Freemantle N, Sheldon TA, House A, Watson P, Long A, Mason J (1993). Selective serotonin reuptake inhibitors: meta-analysis of efficacy and acceptability. Br Med J 306:683-687.

Stenger A, Couzinier JP, Briley M (1987). Psychopharmacology of mildalcipran, a new potential antidepressant. Psychopharmacology 91:147-153.

Thase ME, Hersen M, Bellack AS (1983). Validation of Hamilton subscale for endogenomorphic depression. J Affect Disord 5:2567-278.

Tollefson GD, Holman SL (1994). How long to onset of antidepressant action: meta-analysis of patients treated with fluoxetine or placebo. Int Clin Psychopharmacol 9:245-250. 